\title{
Development of a Semiautomatic Parametric Method for Creation of an I-BIM Model of a Tunnel for Use in FEM Software
}

\author{
Robert Klinc (iD, ${ }^{1}$ Dani Gabršček, ${ }^{2}$ Jure Česnik, ${ }^{3}$ Marko Žibert, ${ }^{3}$ Martin Hostnik, ${ }^{3}$ \\ and Janko Logar $\mathbb{D}^{1}$ \\ ${ }^{1}$ Faculty of Civil and Geodetic Engineering, University of Ljubljana, Ljubljana, Slovenia \\ ${ }^{2}$ iC Consulenten Ziviltechniker, Bergheim bei Salzburg, Austria \\ ${ }^{3}$ ELEA iC, Ljubljana, Slovenia \\ Correspondence should be addressed to Robert Klinc; robert.klinc@fgg.uni-lj.si
}

Received 21 August 2020; Revised 19 February 2021; Accepted 25 February 2021; Published 16 March 2021

Academic Editor: Salvatore Antonio Biancardo

Copyright (c) 2021 Robert Klinc et al. This is an open access article distributed under the Creative Commons Attribution License, which permits unrestricted use, distribution, and reproduction in any medium, provided the original work is properly cited.

This paper focuses on the design phase of I-BIM tunnelling projects using Sequential Excavation Method (SEM), in Europe, commonly referred to as the New Austrian Tunnelling Method (NATM), and addresses the problem of coupling geotechnical conditions and tunnelling Building Information Model (BIM) for the preparation of the computational model suitable for the finite element analysis method (FEM). The review of the literature led to the conclusion that an automatic merging of the tunnel model and ground model for use in the FEM software is currently not reliable due to the number of differences between various types of models as they serve contrasting needs. Consequently, modelling becomes a manual task, which is very time-consuming and error prone. In this paper, we present the development of a framework for the semiautomatic transformation of the various tunnelling models and respective ground models into the model suitable for further analysis. We conclude that the import and translation of the geometry into the FEM software are most successful and accurate when the initial I- BIM (tunnel) model is prepared at a level of detail appropriate for a computational model. The result is the I-BIM model, fit for use in the FEM software which speeds up the modelling process and reduces errors. We have shown that it is possible to prepare the geometry of a tunnel in the BIM software, transfer it, and use it in the software for geotechnical analysis. This makes the preparation of the tunnel geometry for FEM analysis much easier and faster. Due to the fast preparation of the geometry of the new model, the approach presented in this research is useful in practice. The applicability of the framework and the framework workflow are both presented through a practical case study.

\section{Introduction}

Transportation infrastructure can be considered the backbone of any economy, as reliable, safe, and efficient movement of goods and citizens greatly enhances economic and social development [1]. Every infrastructure construction project involves many parties, each producing a considerable amount of information during the life of the project. This information is exchanged between project participants in various forms and through different channels. In the desire for a better, more cost-effective project, there are corrections and changes at every step, which means that communication and information exchange between two project participants is an iterative process in which all other participants must also be informed of changes made [2]. Tracking these changes is made more difficult by the volume of information for infrastructural projects. In addition, most changes demand certain tasks to be repeated, requiring more time and effort while at the same time opening up new possibilities for mistakes and miscommunication. Every construction project is iteratively supplemented and modified to meet the requirements of the investors and the criteria of the standards; therefore effective involvement of all stakeholders is essential in order to achieve a good result.

An effective way to improve the quality of the construction process is to use available interoperability 
solutions, especially Building Information Modelling (BIM). This greatly reduces the need to reenter or copy information [3] and ensures that it is used in the correct context. In recent years, it has become possible to represent most of the required resources in the form of different models (e.g., information models, computational models, and ground models) that have been created and prepared by different project participants. As a result, these models carry a significant amount of information and also influence each other considerably. For this reason, the ability to achieve interoperability between multiple models has always been a key issue in the AEC/O industry and is becoming more and more challenging with the development of various industry specific tools [4]. The success of the project depends on the effective exchange and reliable translation of data in various shapes and formats to be used as input, parameters, factors, and constraints which have a decisive influence on design and construction [5].

In order to create a common language for builders and to support an effective and precise exchange of information, standards for the description of buildings were defined, leading to conceptual modelling, product modelling, and finally BIM. However, all these efforts have traditionally been subject to a research push rather than an industrial pull [6]. Turk [7] described this approach from the 1990s and early 2000s as a top-down approach, where something is first defined and only later (commercially) implemented. Time has shown that AEC/O software vendors have developed their own ways of representing buildings and have therefore used bottom-up standardisation [7]. These two different standardisation approaches created a variety of different data formats, which were only later partially interoperable. Nevertheless, the continuous and significant development of software and other related information technology is recognised as a regulator of growth [5].

Costin et al. [1] noted that technologies and methods that were proven and widely adopted in the building industry, BIM in particular, were pushed to be used in the transportation sector as well, but the use of BIM in transportation infrastructure has been slow in its adoption and application. Tunnel engineering is no exception, even though information technology, software tools, and products have been used for the realisation of underground infrastructure projects for decades. Although solutions for repetitive and common issues are known, commercially available products are incapable of supporting the multiscale and multidiscipline aspects required to properly handle large infrastructure projects [5]. Since the focus of most modelling software is on high-rise construction and not on infrastructure, engineers need to adapt and update these tools to their infrastructure needs as much as possible through plug-ins, API scripts, etc.

During tunnel design, one of the essential phases of the project is the computational analysis of the tunnel behaviour (primary and secondary lining). It must be proven that the tunnel meets the criteria set out in the standards with respect to limit and serviceability limit states. This is often done with software for geotechnical analysis using the Finite Element Method (FEM). This software is used to perform a 2D or 3D analysis of the behaviour of the tunnel under various conditions that may occur during the use or construction of the tunnel based upon geological and geotechnical conditions and tunnel excavation and support method. At present, at least two different models are built in parallel during the tunnel design phase. These are, for example, the tunnel information and computational models. The information model includes detailed 3D geometry of the entire tunnel and its components supplemented with data and information, from which engineers create plans, visualisations, bill of quantities, etc. The computational model is created for the needs of geotechnical analysis and consists only of necessary structural geometry, material properties, and construction phases. As these are separate models, every modification means an adjustment of both models, which doubles the work, leading to a loss of resources, such as time and money, and is prone to errors.

The aim of this work is to investigate the question of dual modelling. The research is focused on the transfer of geometry from the information model and model of ground conditions to the tunnel BIM model that would reduce the effort of preparing the geometry for the computational model. Since a great deal of effort is usually invested in preparing the information model of the tunnel and the ground model of the area, it is advisable to use these models also for the FEM analysis as much as possible. An ideal scenario would be a conversion of geometric and other required information from one model to another. In this paper we will try to answer the question whether this is possible and if so, to what extent. Although similar principles could apply to other geotechnical structures, the focus of this paper is on tunnel design and construction.

\section{Background}

This research is focused on solutions for tunnelling. Nevertheless, general approaches may be adapted and applied to the infrastructure or high-rise projects as well.

2.1. Sequential Excavation Method (SEM). The Sequential Excavation Method (SEM), in Europe commonly referred to as the New Austrian Tunnelling Method (NATM), is a concept that is based on the understanding of the behaviour of the ground, as it reacts to the creation of an underground opening [8]. New Austrian Tunnelling Method (NÖT, NATM) was derived from the basic principles of the previously developed English method and is a direct successor to Old Austrian Tunnelling Method and Newer Austrian Tunnelling Method [9]. It was further developed to Newest Austrian Tunnelling Method with yielding slots.

The main feature of the method is the efficient use of the bearing capacity of the surrounding soil and rock. With controlled excavation in steps and initial deformations caused by an opening in the rock mass, an arch effect is created in the rock mass. In addition, the tunnel wall is stabilized with specific geotechnical support methods such as anchors and shotcrete. During the construction work, geotechnical monitoring must be provided to assess the suitability of the chosen support method and determine the 
support type for the next excavation step. The tunnel is most commonly excavated in three phases (see Figure 1): crown (sometimes referred to as top-heading), bench, and invert.

First, a crown, representing the upper part of the tunnel, is excavated. The excavation takes place in steps of about one to two meters but can vary depending on the ground conditions and the excavation technique. The excavation can be carried out by mechanical excavation in softer rock mass or by drilling and blasting in harder rock mass. After excavation, support measures are installed, and the entire tunnel wall is sprayed with concrete (also known as shotcrete) over preinstalled reinforcement. This is called the outer or primary lining and is considered the primary support of the tunnel as it provides the stability of rocktunnel system.

The excavation of the crown is followed by the excavation of the bench, which trails behind the crown excavation at some distance, depending on the geotechnical and other (technology related) conditions. Here the step can be somewhat longer compared to the crown, because the effects of the excavation of the bench are smaller. The excavation is again followed by the application of support measures and spraying of the wall with shotcrete.

Lastly, the lower part of the tunnel, the invert, is excavated. This step usually follows first two with a major delay, as it is normally not critical and sometimes even hinders the transportation of excavated material. As with the two previous steps, the outer shell of shotcrete is usually constructed. If the rock mass permits, shotcrete in the invert can be abandoned and replaced by concrete foundations for the inner lining and the filling concrete in between.

Smaller tunnel cross sections can have only two phases, crown and bench, while larger cross sections might be divided into more phases using side galleries and wedges [10]. After each excavation step, geodetic measurements are made which are repeated daily to form the basis for monitoring of the tunnel behaviour supplemented by geotechnical measurement techniques. The observed behaviour defines the support types and when the displacement rate vanishes, the construction of inner lining can begin. Inner lining is normally done in segments and is followed by the installation of all necessary tunnel equipment such as road pavement or rail track, power supply, fire equipment, egress, and lightning.

2.2. Numerical Modelling of Tunnels. Originally, the design and construction of tunnels were mainly based on experience [11]. Today, experience is complemented by computational analysis of tunnel excavation and support, determining, among other things, the optimal support, which is capable of ensuring the stability of the tunnel-rock system and the structural resistance of the support elements.

The computational analysis of a tunnel can be performed using different numerical methods (e.g., Distinct Element Method (DEM) [12], Boundary Element Method (BEM) [13], Finite Element Method (FEM) [11], and Finite
Difference Method (FDM)) depending on external factors and other boundary conditions. The software used in this research is based on the Finite Element Method (FEM), but the results are applicable to other numerical methods as well since they all require similar geometrical models.

We distinguish between two-dimensional (2D) and three-dimensional (3D) analyses (see Figure 2), and their use depends on the nature of the problem under study. The advantage of $2 \mathrm{D}$ analysis is its simplicity, as we do not analyse the events in the third dimension. At the same time, this is also its disadvantage, as it cannot cover some of the situations needed to prove the stability of the tunnel that occur in 3D space. In general, 3D analysis is more complex and time-consuming than 2D analysis, as it requires larger number of 3D elements with more integration points and normally includes a sequence of excavation stages.

Tunnel modelling is a pronounced $3 \mathrm{D}$ problem because, in addition to the cross-sectional behaviour, the redistribution of stresses in the longitudinal direction to the nonexcavated area in front of the tunnel and to the already supported tunnel behind the front is very important. Tunnel excavation is a $3 \mathrm{D}$ problem, especially in the area of the excavation face, intersections of tunnel pipes, and caverns [11]. 2D analyses of the tunnel excavation are therefore inevitably related to the assumptions and various workarounds. For this reason, 3D analysis is increasingly desirable for more realistic tunnel modelling, and with the development of computers, their computing speed, and software tools integrating new computational methods, the time needed to calculate more complex models is becoming shorter. As a result, 3D analysis is becoming increasingly feasible and desirable, especially for more complex 3D tunnelling problems such as cross-passages, intersections, or caverns.

The first step in preparing the numerical model for analysis is to define its geometry. This is usually a simplification of reality and consists of points, lines, surfaces, and volumes [14], whereby simplifications allow for a faster analysis and do not affect the results. The process of creating the $3 \mathrm{D}$ geometry can be extremely time-consuming, and each further change to the geometry causes a significant amount of additional work and re-work. The tools for drawing the geometry in an analysis program can be far inferior to the tools in CAD programs, more so for tunnels, therefore the geometry is usually prepared externally and imported via exchange formats into the analysis program, where it is supplemented accordingly. In building construction, the emergence of information modelling and BIM ideology has created the option for digital exchange of 3D models. This also means the use of existing geometry from an architectural or information model which can, at least theoretically, greatly simplify and accelerate the process of preparing a model for FEM analysis.

The sequence of steps to prepare the model for numerical analysis depends on the software used and is generally as follows: 

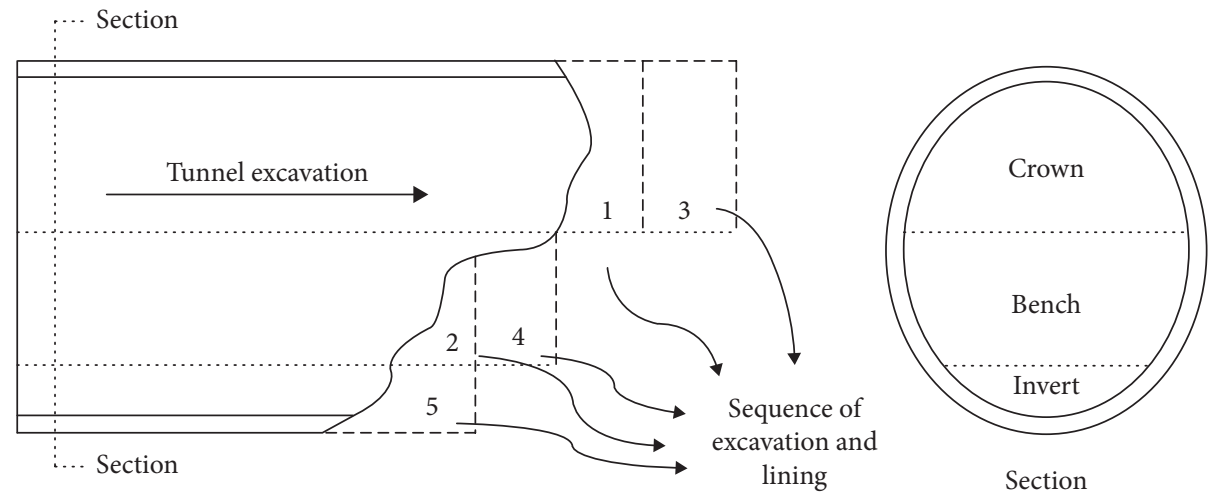

Figure 1: Example of excavation phases of the Sequential Excavation Method (SEM).

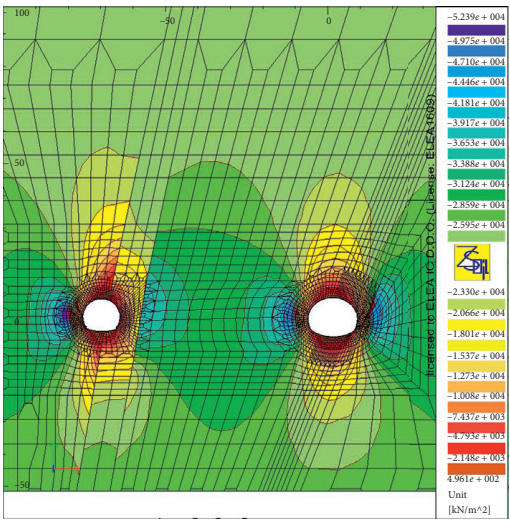

(a)

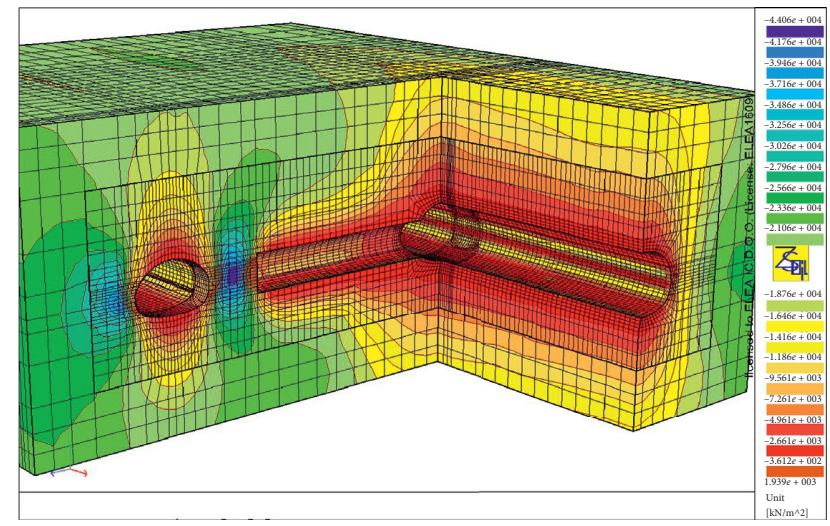

(b)

Figure 2: Example of 2D (a) and 3D (b) FEM analysis of stress state in the surrounding rock.

(i) Definition of the boundary conditions, for example, points or surfaces with prescribed displacements and/or loads

(ii) Determination of the material properties of geometry blocks

(iii) Discretization of geometry into finite elements, which together form a finite element mesh

(iv) Discretization of the structure over time (determination of the excavation phases and sequence of support installation)

This prepares the model for the numerical calculation. The calculation time can vary depending on the number of finite elements, number of excavation steps, the type of finite elements used in the model, and the type of analysis performed.

The calculation is followed by an analysis of the numerical results and the final solution depends on the knowledge and experience of the engineer. If the results obtained are meaningful and pass the engineer's judgement, it means that the chosen solution is appropriate; otherwise the proposed solution must be adapted, and the model must be modified either by changing the support system or by changing the elements' material, supports dimensions, or geometry. Modification of material parameters for rock and support elements is, in principle, simple and fast. On the other hand, changes of dimensions and geometry can pose a greater challenge. Changing the cross section of a $1 \mathrm{D}$ column element is fast because line remains a line; only the assigned cross section is different. The same applies to the thickness of the 2D element. However, changing the geometry of the 3D element always requires remodelling and recreation of the finite element mesh. Changes in geometry and dimensions may also occur later in the design process, so the flexibility of the model design is required. A considerable amount of time can be saved when preparing and modifying the computational model if the geometry from the information model is used [14].

Due to all the advantages presented, this paper is only concerned with the preparation of the 3D model suitable for $3 \mathrm{D}$ analysis.

2.3. Geotechnical Finite Element Software Packages. There are many finite element analysis software solutions out in the market. They differ in the use of finite element types, the type of analysis they can perform, the approach to data exchange, and so on (see Table 1). Some programs allow engineers to import more complex shapes of geometry; others have better ways to automatically mesh with different finite element shapes and create a more optimised or detailed geometry. 
TABLE 1: List of software packages mostly used for geotechnical analyses.

\begin{tabular}{|c|c|c|c|c|}
\hline Name & Developer & Type & Highlights & Source \\
\hline Midas GTS & $\begin{array}{c}\text { MidasIT Engineering } \\
\text { software }\end{array}$ & FEM & $\begin{array}{l}\text { It uses mathematically defined geometry and Boolean operations on geometry and } \\
\text { allows the import of STEP, IGES, and DXF files. It uses a hybrid finite element } \\
\text { mesh, which means that it has the possibility to use a tetrahedral and a hexahedral } \\
\text { mesh simultaneously. It is able to automatically create a mesh of finite elements on } \\
\text { any geometry }\end{array}$ & [15] \\
\hline $\begin{array}{l}\text { DIANA } \\
\text { FEA }\end{array}$ & DIANA FEA BV & FEM & $\begin{array}{l}\text { Intended for the analysis of geotechnical objects. It uses mathematically defined } \\
\text { geometry with Boolean operations on the geometry. DIANA uses a hybrid finite } \\
\text { element mesh. In addition to the basic IGES and STEP file formats, it also allows } \\
\text { the import of Autodesk DWG file formats }\end{array}$ & {$[16]$} \\
\hline Zsoil & Zace & FEM & $\begin{array}{l}\text { It allows engineers to import an older DXF record geometry that contains only } 1 \mathrm{D} \\
\text { elements. It uses quadrangular finite elements for surface meshing and hexahedral } \\
\text { and prismatic finite elements for volume meshing. The grid of finite volume } \\
\text { elements must be created manually, which requires a lot of time }\end{array}$ & {$[17]$} \\
\hline Plaxis & Bentley & FEM & $\begin{array}{l}\text { For the needs of tunnelling, it uses the geometry of arcs and lines with which it can } \\
\text { create cross sections and allows you to import CAD geometries. It uses triangular } \\
\text { elements with six or fifteen nodes to represent surfaces and tetrahedral elements } \\
\text { with ten nodes to mesh volumes. It allows you to automatically create a grid of } \\
\text { finite elements on any geometry }\end{array}$ & {$[18]$} \\
\hline $\begin{array}{l}\text { FLAC/ } \\
\text { FLAC3D }\end{array}$ & $\begin{array}{l}\text { Itasca Consulting } \\
\text { Group, Inc. }\end{array}$ & FDM & $\begin{array}{l}\text { FLAC3D (Fast Lagrangian Analysis of Continua in } 3 \text { Dimensions) is a numerical } \\
\text { modelling software for geotechnical analyses of soil, rock, groundwater, structures, } \\
\text { and soil support }\end{array}$ & [19] \\
\hline $\begin{array}{l}\text { UDEC/ } \\
\text { 3DEC }\end{array}$ & $\begin{array}{l}\text { Itasca Consulting } \\
\text { Group, Inc. }\end{array}$ & DEM & $\begin{array}{l}\text { 3DEC is a 3D numerical modelling code for advanced geotechnical analysis of soil, } \\
\text { rock, groundwater, structural support, and masonry. The numerical formulation is } \\
\text { based on the Distinct Element Method (DEM) for discontinuum modelling. UDEC } \\
\text { is the two-dimensional version }\end{array}$ & {$[19,20]$} \\
\hline
\end{tabular}

An important feature for the analysis of infrastructure facilities is the ability to model the soil and rock mass. The difference between high-rise and infrastructure projects is that the latter have a greater impact on the environment and their solutions depend upon the local ground conditions. For high-rise projects, it is often assumed that they have a simpler support structure and in some extreme situations that the foundations are fixed. This assumption does not apply to tunnels, as they are constructed entirely below the surface and the ground surrounding the tunnel acts both as load and as part of the load-bearing structure of the tunnel. Another difference is that load-bearing structures for highrise usually consist of standard building blocks, such as columns, slabs, walls, and beams, usually with simple shapes. Tunnel cross section consists of arched elements for shotcrete with variable thickness mixed together with linear elements for bolts, anchors, and pipes, creating very complex geometry. The geometry of ground layers in which the tunnel is constructed may also be quite complex, especially near the surface or near the faults. For these reasons, it is desirable that the analysis software allows the import of more complex geometries, such as surfaces and volumes.

\subsection{Building Information Modelling and Tunnelling. BIM} focuses primarily on the smooth flow of information throughout the life cycle of the building product and all participants involved in the project. Cerovšek [4] described BIM as a digital representation of an actual building for project communication over the whole building-project life cycle.
Zhou et al. [21] noted that tunnel engineering strives to introduce BIM technology into working practice so that the design, construction, and operation phases of a tunnel project can be influenced. In addition, many once difficult tasks can be carried out flexibly in the later phases, such as refinement of the model design, construction safety, and systematic operation, all of which definitely contribute to improving the design in terms of quality and efficiency. However, costs and work intensity can also be reduced and cooperation between different units can be improved [21].

Costin et al. [1] emphasized that BIM has been used mainly for buildings and other vertical structures due to the fact that vertical construction (e.g., high-rise buildings and engineering structures) is a completely different process than horizontal construction (e.g., bridge, road, and tunnel infrastructure), where each has different processes, components, and techniques from design to construction, operation, and maintenance. A major differentiating factor between vertical and horizontal construction is the coordinate system used. For vertical construction, the Cartesian coordinate system is used as a single reference, while for horizontal construction, multiple stations and alignment curves are used as references [1].

Therefore, BIM software solutions for vertical construction cannot be applied directly to tunnelling, as vertical projects oriented BIM-based software does not comply with the standards and software of tunnelling. Compared to the high-rise buildings, tunnelling is more complex, including complex geological conditions due to uneven terrain, large project scope, and unpredictable factors such as gushing water and fragile surrounding rock [21]. 
Zhou et al. [21] presented the following steps of the implementation process of BIM technology in tunnelling:

(i) Creation of a 3D geological model combined with geological information

(ii) Selection of the tunnel route based on the geological model

(iii) Sections of the route cut for initial parametric design according to the surroundings

(iv) Use of modelling software packages to create a 3D tunnel model

(v) Adding information to the tunnel model, including attributes, descriptions, parameter setting, external links, and link to database storage

2.5. Ground Model. The quality of the tunnel design is closely linked to the level of knowledge of the soil and rock conditions, which is related to the scale of the investigations. Unforeseen ground conditions affect the safety of the tunnel, its construction time, and project's final cost. Ground investigations are crucial for the proper design of tunnels as the tunnel alignment, typical cross sections, and main construction method highly depend on the results of these investigations. For example, the tunnel axis can be adapted to the ground conditions, which minimizes construction costs and reduces risks [22].

The ground model integrated into the BIM software tool is based on soil and rock mass investigations and should be constantly updated when new geological, hydrogeological, and geotechnical information becomes available [22, 23].

2.6. Interoperability. A typical construction project involves many people from different disciplines. Traditionally, information is exchanged either verbally or via two-dimensional drawings and other documents. This means limited participation and the risk of human error [24]. Even if we disregard misunderstandings and other communication errors, many errors exist due to misaligned design of different systems. Those errors are extremely hard to find with traditional methods using 2D drawings but are easily detected using 3D models through collision detection. Today, everyone involved in the project uses a computer and their own software that produces heaps of information. The exchange of produced information between participants is therefore critical to the success of the project, be it information of a geometric or nongeometric nature. BIM technology is based on the interoperability of different domain- and discipline-specific software tools. However, due to the many software vendors and the different ways of working, the exchange of digital information remains a challenge [21].

According to Rácz and Olofsson [25], requirements for interoperability are the following:

(i) Reuse of information: this is the main objective of the link between BIM and FEM. The connection should allow the import and export of defined concepts with minimal data loss and the redefinition of existing information. (ii) Acceleration of the work process: this refers to the above point, as the use of existing information saves the time of its redefinition.

(iii) Improved quality: due to the sharing of same information between programs, the human factor that can cause errors when reentering information is eliminated.

(iv) Change management: track changes and update the model, removing old information.

2.7. Interoperability Formats. Each software tool has its own native file format. For this reason, it is necessary to have a file format that is supported by several software tools or an open-source neutral format. The data from the program is stored in the chosen format and then read in another program that is able to interpret this data set, convert it into its own data format, and use it.

Table 2 shows the properties of the four data formats that are among the most commonly used in practice.

Trust in the transfer process between software packages from different vendors is low because undetectable errors still lead to results, although faulty ones. In addition, once the geometry has been imported, there may be a lot of work involved in further model preparation, for example, in the assignment of materials and construction phases or even remodelling. Through buildingSMART use cases for IFC, it is suggested that the IFC format should also be used for importing into different FEM analysis programs, but in practice the results of this transfer vary and are at best not optimised and at worst erroneous. The process of importing larger and more complex files can also take a long time and require a lot of computer memory. Some programs work better together than others, but most do not, which can lead to professionals using incompatible programs and making it impossible to transfer information between them. Buying a new program is undesirable, as it leads to additional costs for purchase, staff training, etc. Solutions are often the result of collaboration between software vendors who develop solutions in the form of plug-ins or direct connections, but unfortunately this does not contribute to open standards, as they usually rely on proprietary data formats.

The BIM standardisation of tunnels is still in its infancy. The new version of IFC (IFC 4.0) already allows for the analytical representation of geometry and parametric shapes. However, since its implementation by software vendors is slow, different interoperability approaches need to be used for analysis.

It is also important to answer the question of what the IFC data set is intended for. The complex structure of the IFC file format and the public pressure for its implementation may be partly responsible for this ambiguity. The IFC file format is primarily intended for data transfer and model comparison. To the outside world, the presence of an IFC file in the BIM modelling software as well as in the numerical analysis software seems to imply that geometry is exchanged automatically and without errors. While it is true that IFC file notation allows the transfer of both geometric and nongeometric information, the IFC file format is currently not 
TABLE 2: Comparison of data formats [26].

\begin{tabular}{|c|c|c|c|c|}
\hline $\begin{array}{l}\text { Comparison } \\
\text { points }\end{array}$ & DWG & DXF & IGES & IFC \\
\hline Stands for & DraWinG & $\begin{array}{l}\text { Drawing eXchange } \\
\text { Format }\end{array}$ & $\begin{array}{l}\text { Initial Graphics Exchange } \\
\text { Specification }\end{array}$ & Industry Foundation Classes \\
\hline Expressivity & $\begin{array}{l}\text { 3D geometries, colours, text, } \\
\text { \& layers }\end{array}$ & $\begin{array}{l}\text { 2D geometries, colours, } \\
\text { text, \& layers }\end{array}$ & $\begin{array}{l}\text { 3D geometries, colours, } \\
\text { text, layers, and } \\
\text { mechanical \& FEA data }\end{array}$ & $\begin{array}{c}\text { 3D geometries \& alphanumeric } \\
\text { semantic information about } \\
\text { building components }\end{array}$ \\
\hline Interoperability & $\begin{array}{l}\text { Proprietary to AutoCAD }{ }^{\circledR} \& \\
\text { some similar software } \\
\text { holding Autodesk's license }\end{array}$ & $\begin{array}{l}\text { Neutral (open source to } \\
\text { most of CAD, CAE, \& } \\
\text { CAM software) }\end{array}$ & $\begin{array}{l}\text { Neutral (open source to } \\
\text { most of CAD, CAE, \& } \\
\text { CAM software) }\end{array}$ & $\begin{array}{l}\text { Neutral (open source to most of } \\
\text { CAD, CAE, \& CAM software) }\end{array}$ \\
\hline Encoding & Binary & ASCII & ASCII & $\begin{array}{c}\text { Data definition language: } \\
\text { EXPRESS }\end{array}$ \\
\hline Complexity & $\begin{array}{l}\text { Handles 2D \& 3D (solid) } \\
\text { objects }\end{array}$ & $\begin{array}{l}\text { Handles } 2 \mathrm{D} \text { vectors only } \\
\text { (does not handle solid/ } \\
\text { surface elements) }\end{array}$ & $\begin{array}{l}\text { Handles } 2 \mathrm{D} \& \text { \& } \text { (solid) } \\
\text { objects }\end{array}$ & Handles 2D \& 3D (solid) objects \\
\hline
\end{tabular}

intended to transform the geometry of the information model into the geometry of the computational model [3].

2.8. Interoperability of BIM and FEM Software. One of the most important and difficult exchanges of models and information in general takes place between the informationrich 3D representation of an object and its computational model. The latter is created for the computational analysis, which includes the calculation according to one of the numerical methods, in our case the Finite Element Method. Since the design of buildings and infrastructure is an iterative process, changes in geometry, materials, and other parameters are inevitable. If there is no connection between the CAD and FEM model, all changes in the computational model must be synchronised manually, which can be a tedious and time-consuming process [27].

The method used to describe the geometry imported into the analysis program has a considerable influence on the quality of the finite element mesh and the freedom to create this mesh. During the preparation of the finite element mesh, the analytical geometry is transformed into a discretized one, but the discretization is controlled according to the needs of the Finite Element Method. We do not have this freedom if we use the already discretized geometry (e.g., triangulated model in IFC format). The finite elements must adapt to the discretized geometry, which may make the geometry of the model or the finite element mesh unsuitable. If the density of the points describing a discretized geometry is too low, the geometry may be too distorted, and if the density of the points is too high, the problem of the size of the numerical model arises. Problems may also occur due to the discretized geometry of elements, which may be unsuitable for analysis as they may cause numerical problems, or due to the transfer of $3 \mathrm{D}$ elements to $2 \mathrm{D}$ or $1 \mathrm{D}$, where the problem of axis contact occurs. This is especially problematic for radial element such as tunnel excavation steps and lining, since those are usually discretized into sharp triangles which must be avoided for numerical analyses.
Traditionally, model conversion is the task of a structural or geotechnical engineer. Their knowledge, affinity and experience are difficult to convert into an algorithm. Although there are cases where automatic conversion is possible, there is currently no general automatic conversion for all possible 3D shapes [28].

The market offers a large number of software packages able to connect BIM modellers with software packages for FEM analysis. But as a number of software solutions enable connections based on the DWG or DXF format, this process leads to the loss of information on materials and their properties. Full connectivity of models is achieved only when information exchange is enabled in both directions. This means that the required information is transferred to the FEM analysis software and the results are eventually passed back to BIM. This ideal integration is shown in Figure 3.

In theory, with perfect integration of BIM and FEM, a model is created from information about materials, geometry, etc. in BIM modelling software and seamlessly transferred to a program for analysis. In the event that the results of FEA show that the design is appropriate, this data is then passed back and becomes part of the BIM model. If the analysis of the computational model is not successful, the model is corrected and reevaluated in the analysis software. The changed characteristics are then also changed in the BIM model.

In reality, the process of automatic conversion of information model into a computational model is difficult. However, in some specific, simpler cases, BIM tools are able to achieve this. Special plug-ins for BIM modellers are also available on the market to facilitate the process of conversion between the information model and the computational model. One such example is the link between Autodesk Revit [29] and Robot structural analysis [30], but this is mainly due to the use of a proprietary data format and the limited scope of analysis. FEM analysis experts generally prefer specialized programs because they offer more specific analyses and several different models of material behaviour. The analysis parameters are also more controlled, and the accuracy of the 


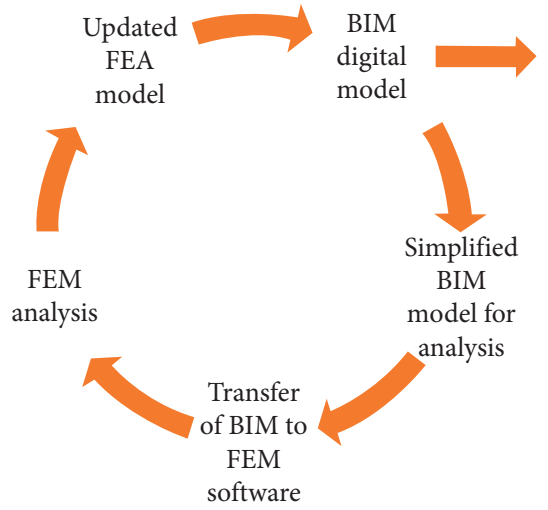

FIGURE 3: Ideal integration of BIM and FEM software (based on [24]).

results is better in such specialized software [24], but the data transfer from BIM model is more difficult.

\section{Proposed Method for the Creation of a I-BIM Model of a Tunnel for Use in FEM Software}

Preparation of the 3D geometry for excavation and outer or inner lining of a tunnel that can be used directly for FEM analysis is highly problematic, as it requires a considerable amount of manual work that is then repeated when the geometry of the tunnel changes. An optimization of this workflow is therefore essential. It would be possible to use $\mathrm{BIM}$ to transfer the $2 \mathrm{D}$ geometry to $2 \mathrm{D}$ analysis, but since tunnelling is a $3 \mathrm{D}$ computational problem, especially near tube crossings and excavation face, $3 \mathrm{D}$ analysis is more suitable in practice and increasingly desirable. Computer programs and hardware are also improving, which reduces the time required for 3D numerical analysis even with a large number of finite elements.

Both literature review and project experience show that the effort required to supplement and verify an imported model that has deficiencies can be almost as high as the effort required to create a new model. During the transfer of the geometry and the subsequent model corrections we are never sure that we have corrected all the errors. This is not the case with the FEM model developed in FEM software, where no transfer-related errors have to be searched for.

Interaction between BIM and FEM analysis can be done through direct or indirect connections. Interoperability of BIM and FEM in commercially available applications has been demonstrated for both direct and indirect connections, but only for simple design examples. In case of higher complexity, the results of data transfer are hardly satisfactory. Overall, interoperability between BIM and FEM is at a stage where collaboration is possible to a certain extent but there is no complete link, especially for infrastructural projects.

To summarize,

(i) The transfer between the models is not straightforward, it often does not work, and there are errors that need to be corrected later. However, the model must be mathematically descriptive and further simplified in order to create a better FEM analysis.

(ii) BIM modelling software tools are more effective and user-friendly at creating a tunnel model than the modelling tools in FEM analysis software.

(iii) If simplified, tunnel geometry can be created automatically, thus significantly reducing the time needed for modelling. Additionally, simplified geometry makes the model more suitable for structural analysis.

For all of the abovementioned reasons, our intent was to improve the preparation of the computational model for $3 \mathrm{D}$ analysis using BIM modelling tools, thus bridging the gap between different programs and processes.

3.1. BIM Model of a Tunnel. The process of creating a tunnel BIM model depends on the choice of software. For the purposes of this study, the workflow with Autodesk software is described. This is in line with real-life scenario, as DWG file format is still heavily relied on, since the use of it eliminates translation-based errors.

The first step is determining the tunnel alignment or axis. It is usually modelled using software specialized for road or railway modelling tools such as Civil $3 \mathrm{D}$ and later on imported into other software, such as Revit, for tunnel solid modelling. Since Revit does not contain parametric building blocks ("Revit families") for tunnels, these must be created first. These are single, complex, but parametrically descriptive building blocks. Main parameters that define such objects are the length of each excavation step, the angle at which the elements fit together according to the axis, the material the block is made of, the thickness of the concrete support, additional support measures, etc. The parametric blocks, which represent parts of the tunnel, are then placed along the axis.

The level of complexity of these blocks varies based on their uses. The building block for excavation bodies describes a simple solid, which is mainly defined by the cross section geometry of the excavation phase and the length of the excavation step. A correct solid geometry also requires a contact angle with the next element and two points that control the placement of the element in $3 \mathrm{D}$ space.

The complexity of modelling the outer lining and additional support measures is somewhat higher. The model consists of the bodies of the geometry of the outer lining and the length of the excavation step. The angle of contact with the next element and the inclination of the tunnel are also important. In the case of additional excavation support measures, these should also be modelled, depending on the stage of development of the model. At a low level of development, the information can only be recorded as additional attributes to the solid, while at a higher level of development the support element is represented with $3 \mathrm{D}$ geometry. For example, rock bolts can be either modelled or represented as an attribute, where the number and type of bolts are added to all other attributes of the primary lining. The decision has to be made-which of the approaches 
works best based on the complexity of the situation and the size of the model?

The highest complexity lies in the modelling of the inner lining. At present, the complexity is still too great to be included in the FEM analysis (see Figure 4(b)) and, since most analyses of the inner lining are not done in $3 \mathrm{D}$, is also not crucial.

3.2. Proposed Method. The method we propose uses the possibilities offered by the Dynamo tool within Civil 3D. It allows us to set up a workflow that automatically prepares the geometry of the tunnel, with the generated geometric model being mathematically descriptive and therefore ready for FEM analysis. The entire geometry of the tunnel is modelled as a whole and only later divided into excavation phases and steps. This ensures the correct contact of neighbouring elements (e.g., excavation steps) and automates the process of preparing the geometry suitable for transfer to the FEM analysis software. Time needed to prepare the model geometry for analysis is thus significantly reduced.

The preparation process is divided into creation of the tunnel geometry and creation of the geometry of ground layers.

First, the process of preparing the tunnel geometry is described. The advantage of using BIM is in the simplicity of modelling the geometry compared to the tools within the FEM analysis program. To create a 3D tunnel geometry, the following input is needed:

(i) 2D geometry of all cross sections of the tunnel: these are represented by $2 \mathrm{D}$ contours of the excavation.

(ii) 2D geometry of the boundaries between the individual phases of the tunnel excavation: these are the boundary between the crown and the bench and the boundary between the bench and the invert.

(iii) Mathematically descriptive 3D geometry of the tunnel axis or alignment.

(iv) Stations where the individual cross sections of the tunnel are located: they are only required in places where there is a change in the support type.

(v) Excavation steps of each excavation phase.

(vi) Names used to identify the geometry of the excavation contour.

The geometry of the excavation contours and the course of the tunnel axis have to be designed in Civil 3D. This must be drawn manually and has to be prepared for the creation of the geometric and information model. All other data is numerical and is included in a spreadsheet in Microsoft Excel. This data is imported into Dynamo where it serves as input for tunnel modelling parameters that guide the Dynamo script and automatically draw the tunnel at the location of the tunnel axis. This prepares the tunnel geometry for import into the DIANA FEA. The geometry is transferred through DWG containing the tunnel excavation bodies. This reduces the possibility of errors, as it is only a single conversion (DWG-DIANA FEA), instead of a double conversion (DWG-IFC-DIANA FEA). Another reason is that the implementation of the IFC file format in Civil 3D is outdated, and the geometry export does not remain analytical, but rather changes to a discretized format.

This is followed by the definition of the ground layers. Since Leapfrog software uses triangulated geometry, it must be modified or recreated for analysis purposes on the basis of mathematically descriptive geometry. The boundaries between ground layers have to be transformed. The resulting model is ready for transfer and analysis in DIANA FEA. The scheme of the workflow and data transfer is shown in Figure 5.

Other information must be entered into DIANA FEA manually. The ground model is used to extract information about the material properties of individual ground layers attributed to the solid imported into DIANA FEA. Information about the excavation sequence is obtained from the information model. During the import, time of excavation is assigned to each element, resulting in DIANA FEA preparing the excavation phases.

3.3. Software Tools Used. For the purpose of this research, several software tools, described below, were used.

Autodesk Civil 3D is one of the most advanced BIM tools for infrastructure design [23]. As a member of Autodesk package, it supports collaboration between related programs including Revit and Infraworks, thus enabling BIM tunnelling design. Interoperability can be achieved through proprietary DWG file format or open-source IFC (and other formats as well). Nevertheless, the best results are achieved with the use of DWG file format, as geometry changes from analytical to discretized when using IFC, which means that the curves are not supported and are approximated by straight lines. Such geometry is distorted and can lead to undesirable errors in the automatic generation of a finite element mesh.

Autodesk Dynamo for Civil 3D-a recently introduced visual programming environment-can be used to automate tasks in Civil 3D and enables parametric modelling of tunnels. It can be further enhanced with Python programming language.

For performing FEM analysis, DIANA FEA software package was used. One of the main advantages of this software is its connectivity to Autodesk suite of tools. It can work with DWG proprietary format and is therefore capable of importing mathematically descriptive geometry. Among other strengths of this software is the ability to use the Python programming language to automate various repetitive tasks within the analysis program, along with a very good algorithm for creating a mesh of finite elements, which is able to automatically generate a mesh on any volume, since it uses a hybrid mesh of finite elements (also hexdominant mesh). In addition, the software provider DIANA FEA is developing a plug-in for Autodesk Revit that allows for the transfer and conversion of the geometry into a computational model. However, at the time of our research this plug-in was not mature enough for transferring the tunnel geometry.

Lastly, Leapfrog is a software tool for 3D modelling of the geological structure. The creation of a ground model works 


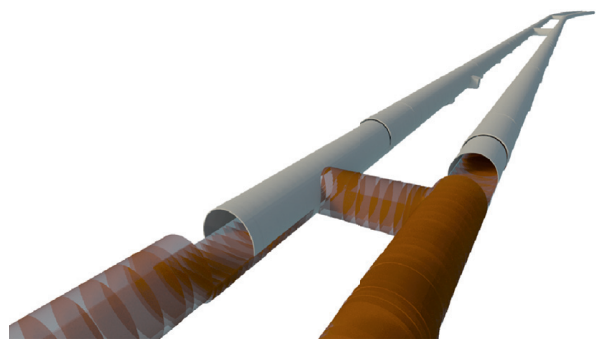

(a)

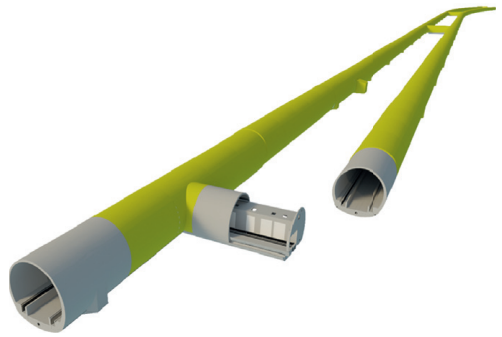

(b)

Figure 4: BIM models of tunnel excavation and support (a) and tunnel inner lining (b).

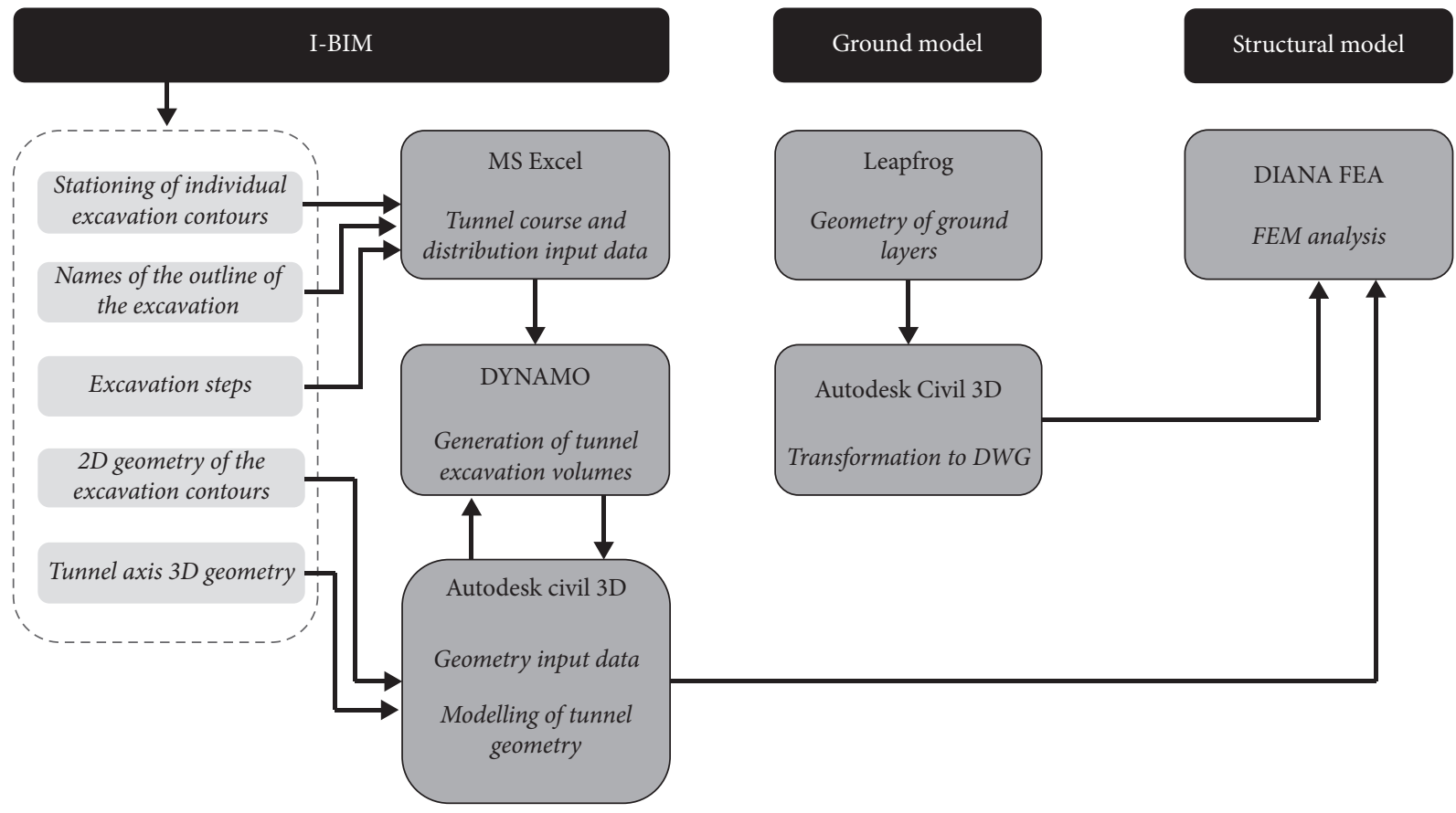

Figure 5: Schematics of the proposed method.

on the principle of implicit modelling. This means that the model is automatically generated based on the input data. This can be data from survey boreholes, elevation points, surface structure, etc. The model is then dynamically updated by adding research information and modifying the interpolation parameters. However, the fact that the geometry of the model is discretized can cause difficulties in the preparation of the finite element mesh. DIANA FEA requires a mathematically descriptive geometry, which is why a workaround was needed. Leapfrog is capable of exporting a DXF file format. It exports areas that represent boundaries between individual ground layers that are regenerated based on mathematically descriptive geometry, for example, NURBS. Using these areas, the solids representing individual ground layers can be generated. Experiments showed that the division of the model into ground layers behaves better when done in DIANA FEA, because small inconsistencies along the contact area between ground layers can otherwise occur. The assignment of material properties is done manually within the DIANA FEA, as the transfer of nongeometric data requires adjustments on all levels of the workflow and was therefore avoided.

3.4. Case Study. The applicability of the proposed workflow is illustrated by tunnel intersection of five tunnel tubes (see Figure 6). Four of these have an excavation course in the horizontal direction and one tube in the vertical direction. The tunnel tube can also be inclined, as only the difference between the courses of the excavation direction is important. In this case study, the main tube of the tunnel is cut by two side tubes intended for the maintenance of the tunnel. One of the side tubes is connected to a shaft that leads to the surface. Both side tubes are connected by a transverse tube.

First, it is necessary to collect all necessary input data and prepare them in a suitable form. Geometric information is collected and prepared in Civil 3D, tunnel course information is collected in an Excel file, and both are combined by a Dynamo script. The IDEF0 diagram in Figure 7 shows the processes involved in preparing the input data. 


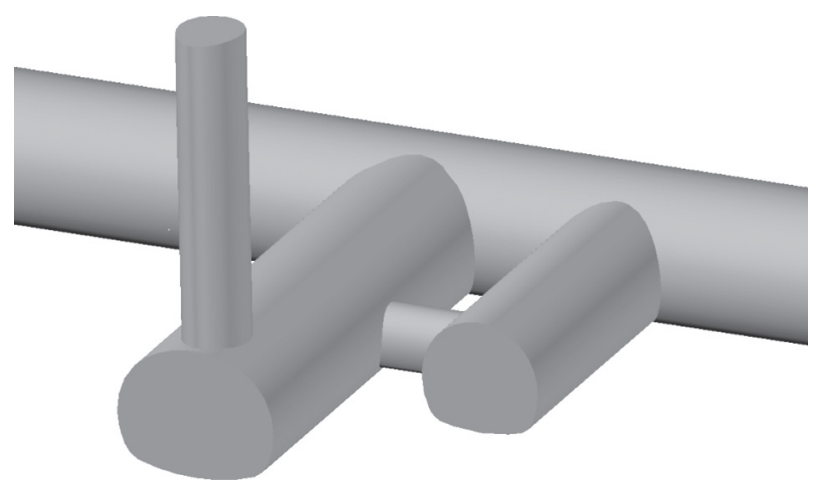

FIGURE 6: Geometry of tunnel intersection case study.

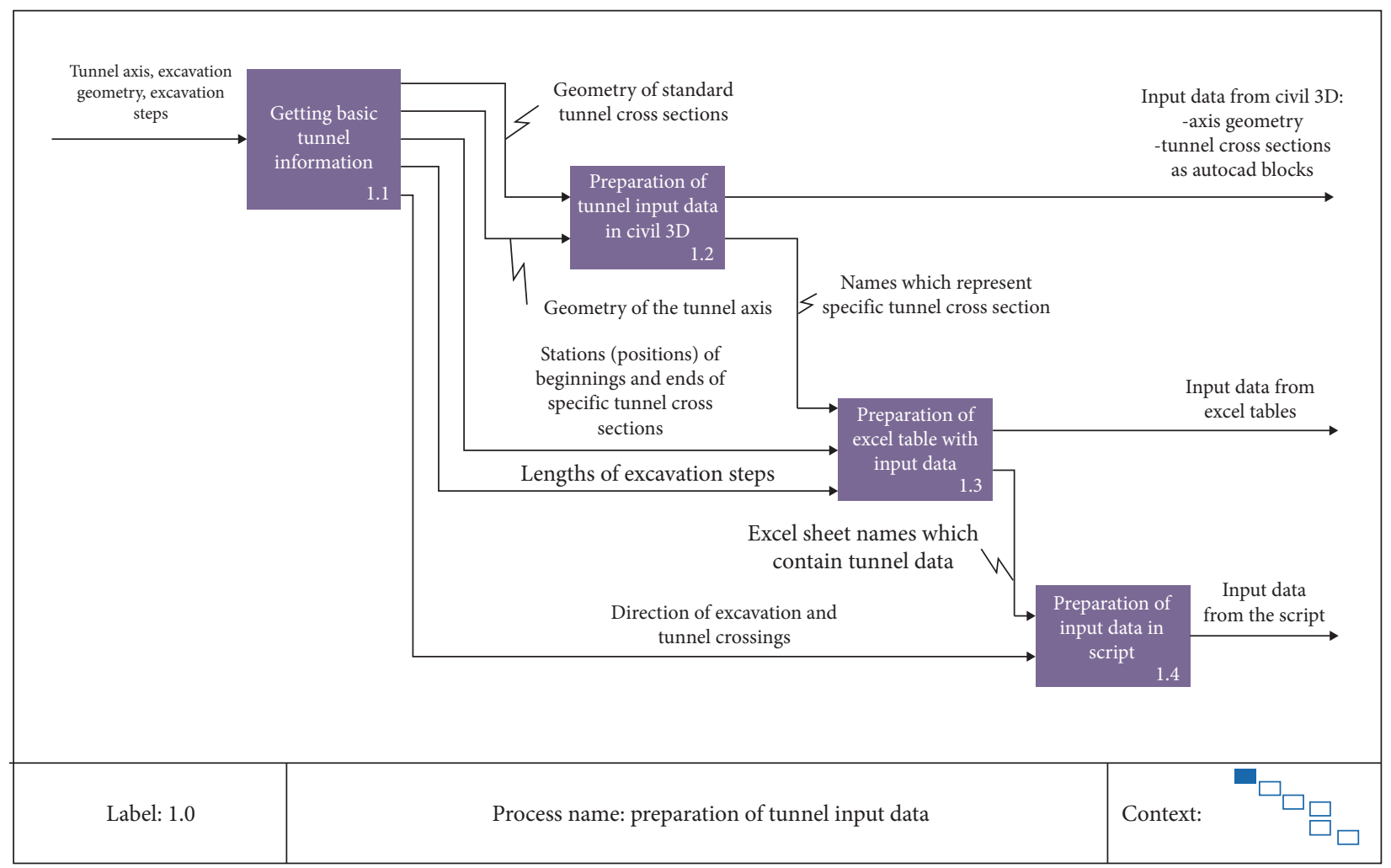

FIgURE 7: IDEF0 diagram: preparation of tunnel input data.

In Civil 3D, the geometry of all tunnel axes and the geometry of the excavation of the different types of supports are defined. It is preferred to use an empty Civil 3D drawing to prepare the model, avoiding importing unnecessary elements into the FEM analysis program. For this case, the maximum length and angle accuracy is used, in order to avoid possible rounding irregularities, preventing individual bodies from being in proper contact with each other, which can lead to errors in the calculation model and incorrect analysis results.

For correct operation, the tunnel axis must be specified as a $3 \mathrm{D}$ or standard planar polyline; otherwise the axis must be redrawn. In this case, the beginning of the axis is where the intersection is located (see Figure 8).
The cross-sectional geometries of the tunnel also need to be defined. These are the lines that represent the outline of the excavation and the outer perimeter of the tunnel support, which are defined using the block library. Special attention must be paid to the orientation of the geometry due to the local coordinates. During the work, it became apparent that the geometry of the entire excavation of the tunnel tube has to be created in one piece and later divided into segments representing the sequential excavation of the tunnel in order to ensure an exact contact between the volumes. In its current form, the script allows the use of three blocks: the cross section of the tunnel represented by the outline of the excavation, the boundary between the crown and the bench, and the boundary between the bench and the invert. If more 


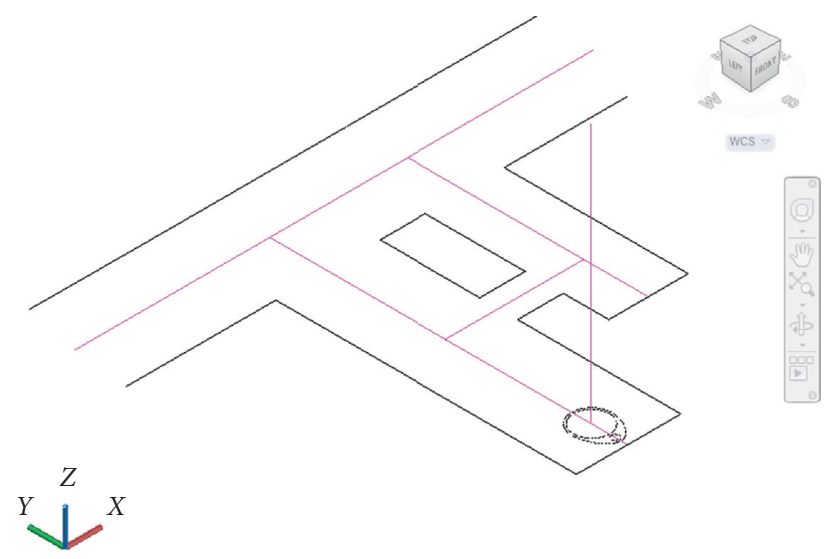

Figure 8: Definition of tunnel axis in Civil 3D.

than three excavation phases are required in the future, the workflow can be improved, and new blocks can be defined to represent new boundaries.

The data on the excavation steps and the distribution of the support types along the tunnel axis are defined in tabular form in Microsoft Excel. The following information is assigned to each tunnel axis:

(i) Length of the excavation steps

(ii) The name that defines the block containing the geometry of the $2 \mathrm{D}$ outline of the excavation

(iii) The start and end stations and any change on the axis (e.g., of support type)

For each tunnel axis, a separate sheet in Microsoft Excel needs to be set up, which contains a table with the necessary data (stationing, length of the steps of the crown, length of the steps of the bench, length of the steps of the invert, and name of the block from Civil 3D).

After Civil 3D and Microsoft Excel input data are complete, some additional information must be added within the Dynamo software environment. In addition to the location of the input spreadsheet, the Civil 3D axis geometry must also be selected. The user must also determine the sequence in which different tubes are excavated and whether the excavation process is horizontal or vertical (in which direction the normal of the tunnel cross section is oriented). The data in the provided spreadsheet and the model in Civil 3D must be consistent.

The prepared input data is read incrementally by Dynamo where it is structured for use in further processes. Lists are created with information on all the start and end stations, the steps of the crown, bench, and invert, and the names of the blocks with the excavation geometry. From here, the workflow is roughly the following:

(i) Calculation of the stations along the axis of the tunnel: local coordinate systems on the tunnel axis are obtained from the calculated stationing

(ii) Creation of elements for subdividing the excavation body: station lists and local coordinate systems are used (iii) Generation of solids: blocks with a defined 2D geometry of the excavation contour are placed on stations with the corresponding starting point, local $x$-axis, and global $z$-axis (gravitational axis)

(iv) The solids of each tunnel axis are divided into prescribed excavation phases and their excavation steps

The Dynamo script developed for this workflow allows the generation of excavation volumes for up to five tunnel tubes (see Figure 9). If more axes are required, the script can be updated with minimal corrections. These mainly concern the influence of one axis on another at the point of intersection.

The result of the described workflow is shown in Figure 10. The Dynamo script generates the geometry of the solids, which can be imported into the selected program for analysis. Each of the excavation phases of each tunnel tube is represented on a separate layer, as this makes it easier to control the display and selection of the solid geometry within Civil 3D and also within the DIANA FEA program, since the layers are preserved during import. The solids are cut into excavation steps defined in Microsoft Excel. In case of changing the geometry or the excavation steps, only the corresponding input has to be changed.

The Dynamo script can be adapted to the needs of any individual tunnel, as each tunnel is unique in terms of geological conditions, geometry, and excavation sequence. As a result, the computational models will also be slightly different, which means that it would be difficult to create a single script for the general case. Therefore, the script has to be adjusted for certain cases.

One example that requires modification is when rock bolts are used as support elements. Manual modelling can take a long time due to the large number of bolts. For this purpose, the Dynamo script was slightly modified as only the content of the block with $2 \mathrm{D}$ cross section geometry is different. Since the rock bolts are 1D elements, their inclusion into the model did not require further subdivision (cutting) of already defined solids. For this reason, it is only necessary to calculate the exact position of a block of rock 


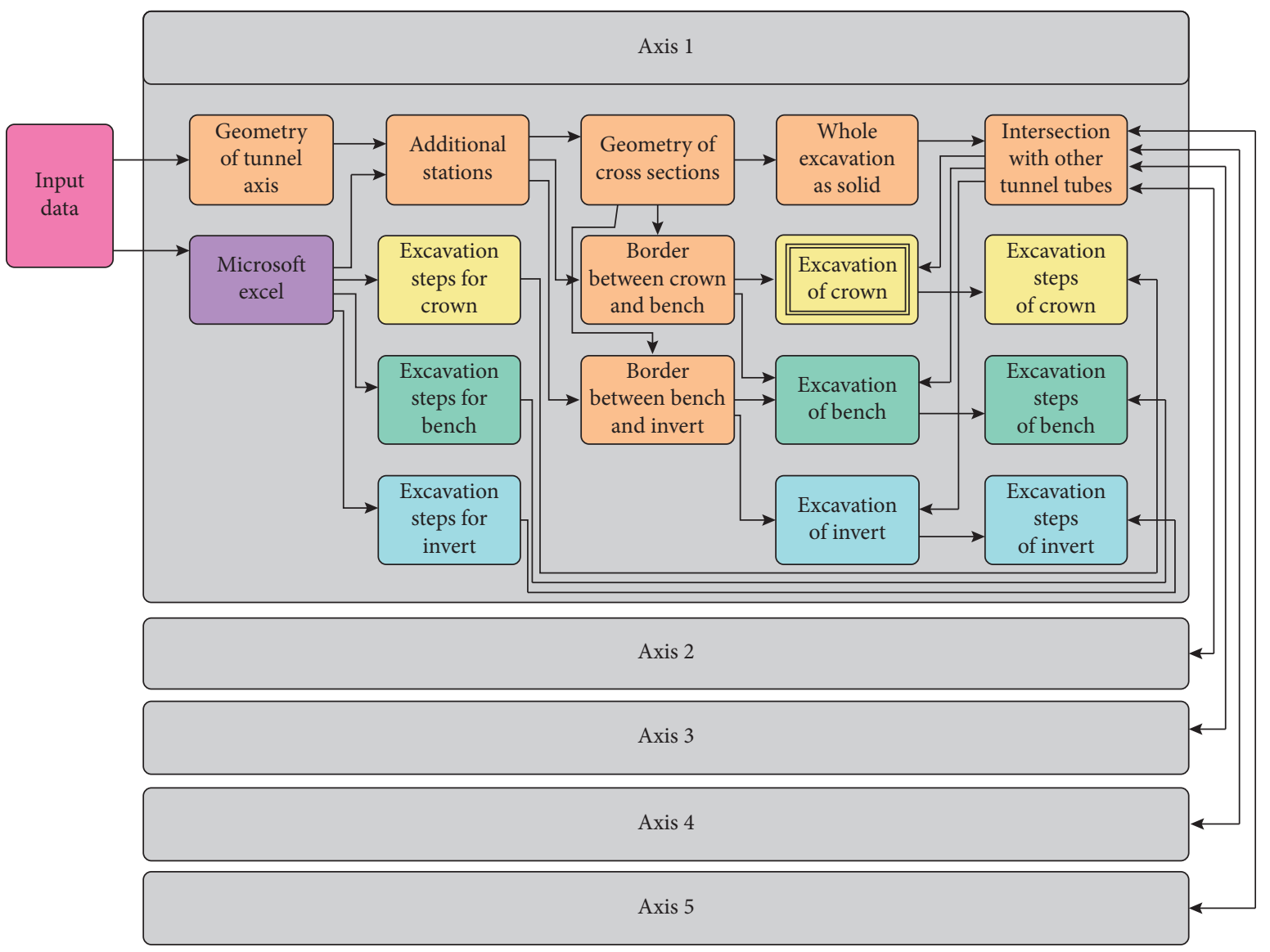

FIGURE 9: Dynamo script algorithm scheme.

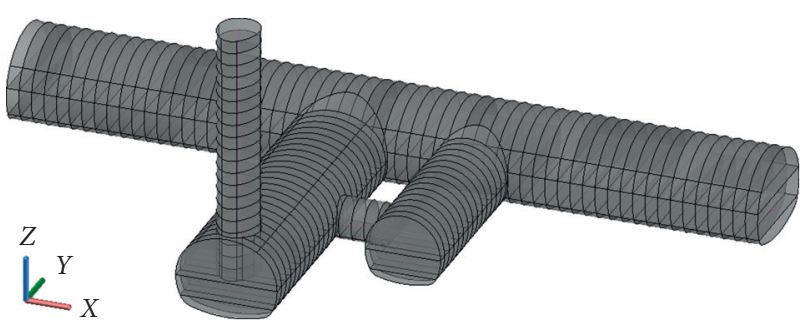

FIgUre 10: Model of a tunnel presented as solid cut on individual excavation steps.

bolts in the cross section. An example of a model with bolts is shown in Figure 11.

It is also possible to model the simplified inner lining, which is defined as a continuous solid over the entire tunnel, which is why no solid cutting process is required here either. An example is shown in Figure 12.

Both Dynamo script customizations are the results of the needs that have arisen in practice. In the future, they could be included in the core Dynamo workflow. Nevertheless, the Dynamo script could become increasingly more difficult to understand, making it harder to update and use later.

Before the use in FEM software, the geometries of the ground layers and of the tunnel in the DWG format are needed. The geometry of the ground layers is transformed into a suitable form by processing the ground model. Solids that represent individual ground layer in the influence area of analysis are needed. The example is shown in Figure 13. Because of the possibility of errors during the import of geometry, a better option is to perform the operations of cutting the entire solid model into material layers within DIANA FEA. Such examples include the excavation of the shaft or the excavation of the tunnel body. Possible errors in importing geometry are usually due to small differences in the way the geometry used by the two programs is represented. Only the necessary surfaces are prepared in AutoCAD or Civil $3 \mathrm{D}$ and later imported together with the geometry to DIANA FEA. Since DIANA FEA uses Boolean operations on polygons, this process is fast. Errors when importing the excavation geometry can also occur at the intersection of two tunnel tubes. If such an error occurs, it is also better to model contacts between different tunnel tubes manually after importing them into DIANA FEA.

This is followed by the import of DWG files with tunnel geometry into DIANA FEA and the cutting of solids representing material layers with a (Boolean) subtraction operation (see Figure 14). This removes the tunnel excavation geometry from each material layer.

The next step is the definition of boundary conditions and the input of material properties. Boundary conditions that limit displacements should be assigned to the outer edges of the layered solids. Finally, a finite element mesh is automatically generated (see Figure 15). 


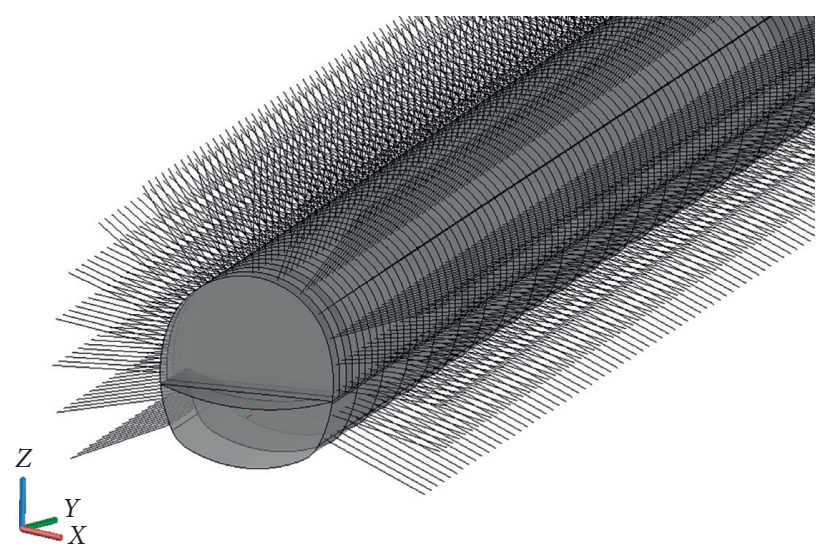

Figure 11: Model of a tunnel with rock bolts.

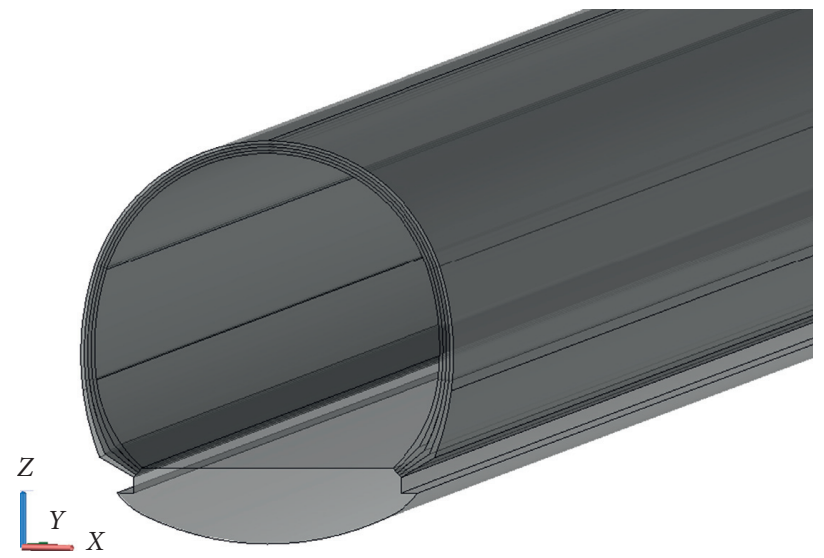

Figure 12: Model of inner lining.

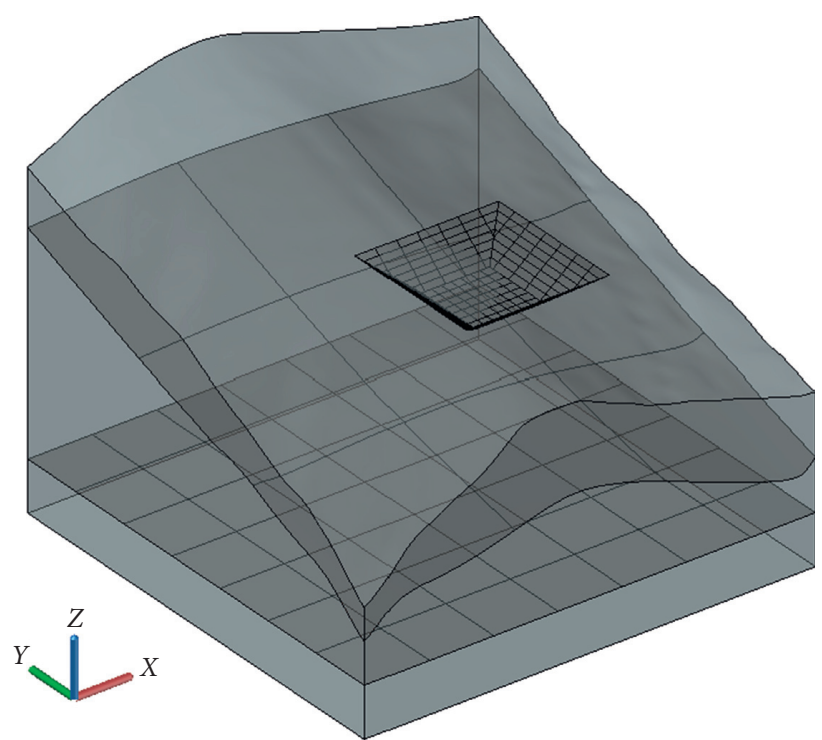

FIgURE 13: Ground model as visualized in Autodesk AutoCAD. 


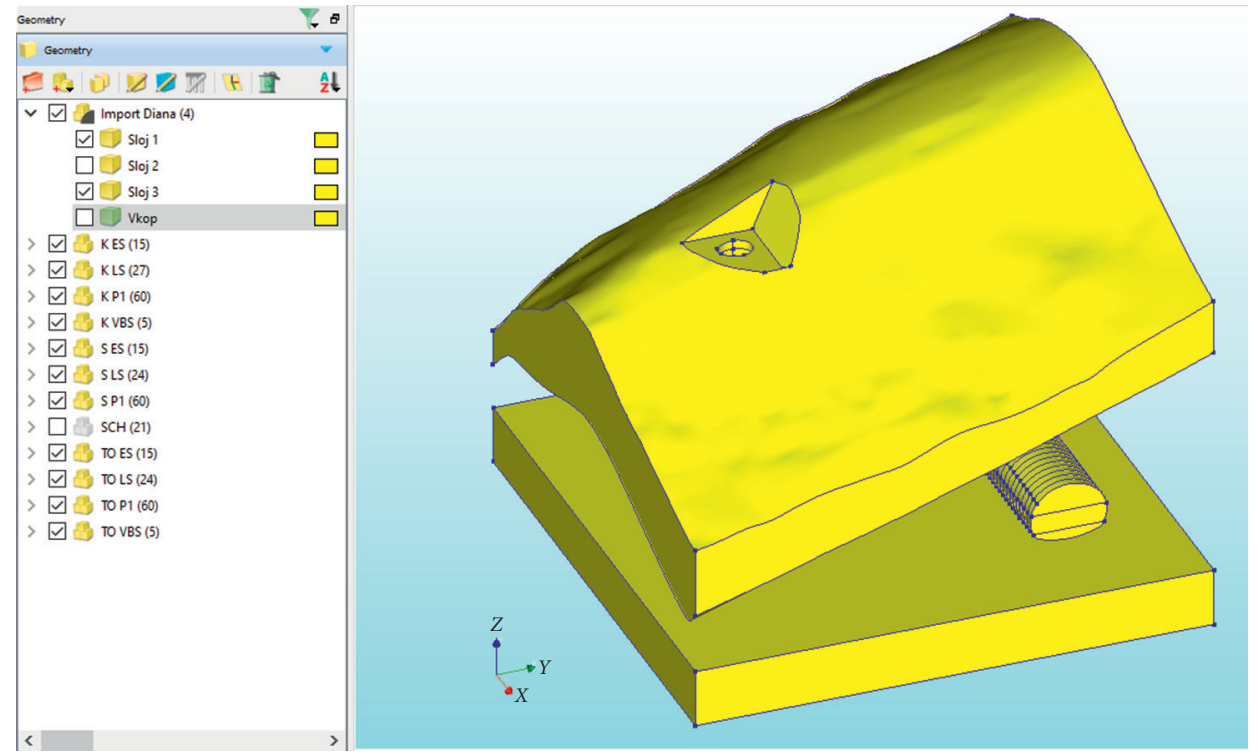

FIgURE 14: Geometry manipulations in DIANA FEA.

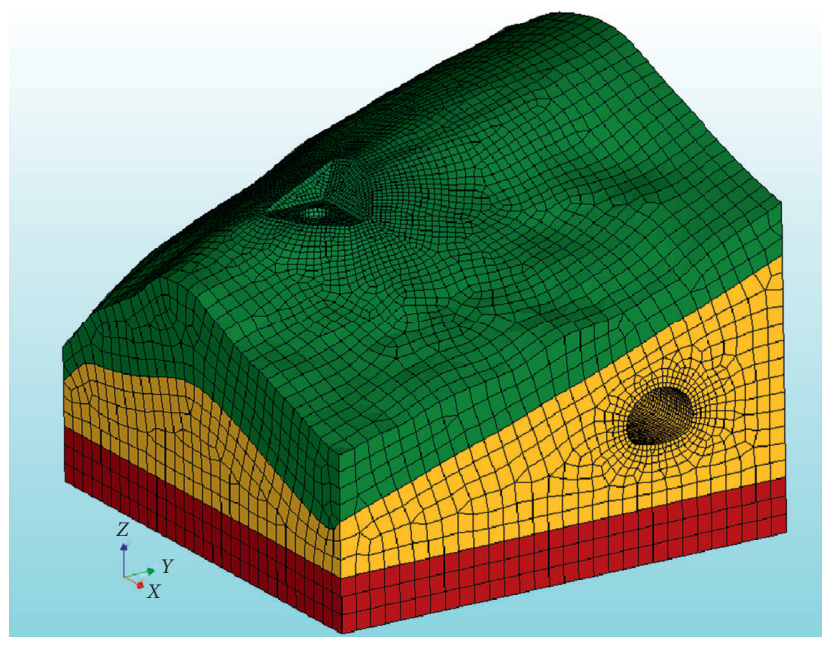

(a)

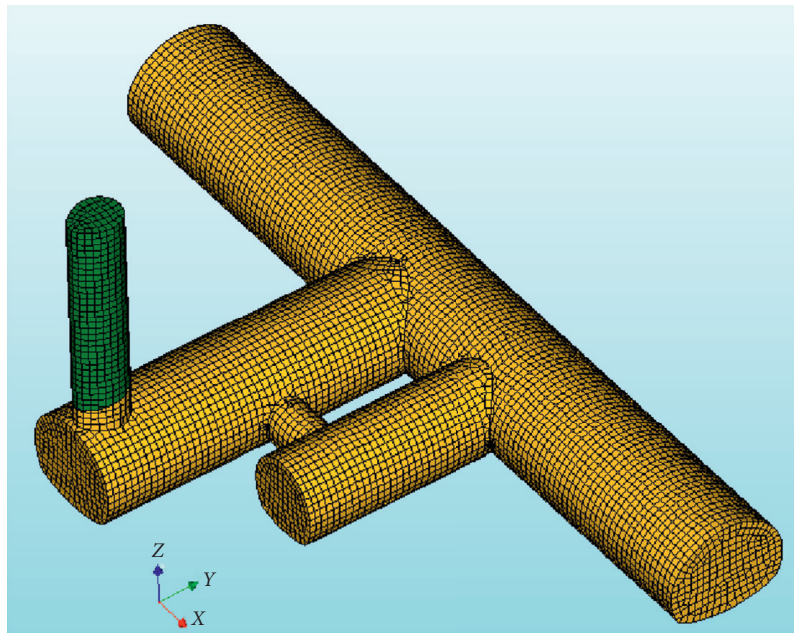

(b)

FIGURE 15: Finite element mesh for tunnel analysis.

The process of modelling the shotcrete outer lining takes only a small amount of time, as shotcrete is usually modelled as a surface on the excavation wall, so the geometry of the outer lining is already known. This is followed by the definition of the excavation steps, which coincides with the calculation phases of the numerical model in which the deformations and stresses are calculated. All the necessary data for the analysis is thus defined and the calculation follows.
An example of deformation pattern after the tunnel excavation is shown in Figure 16. The figure shows a 3D view of the FE geometry with the calculated displacements in longitudinal section along a longer transverse tunnel with one shaft.

Figure 17 shows two 2D cross sections and the calculated total stresses. The cross section on the left runs through the shaft and the one to the right through the main tube of the tunnel and the cross-passage. 


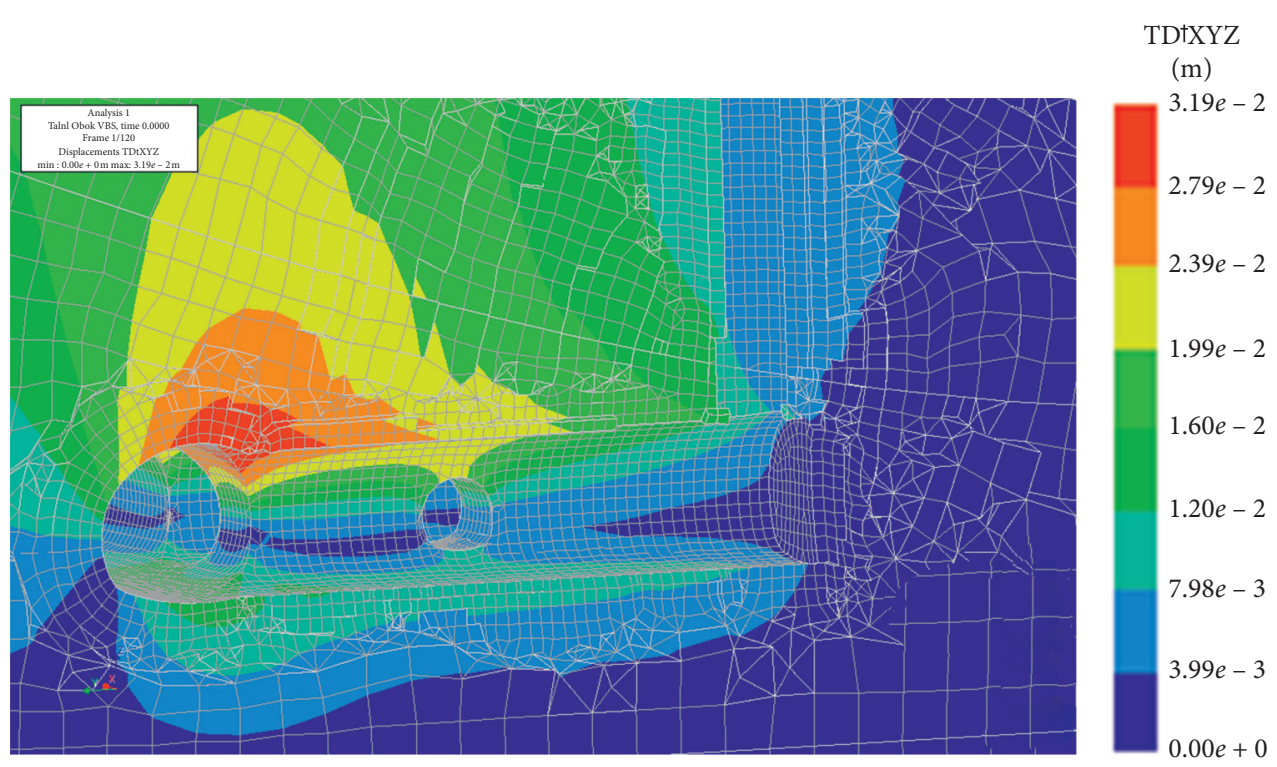

Figure 16: Ground displacements after tunnel excavation.

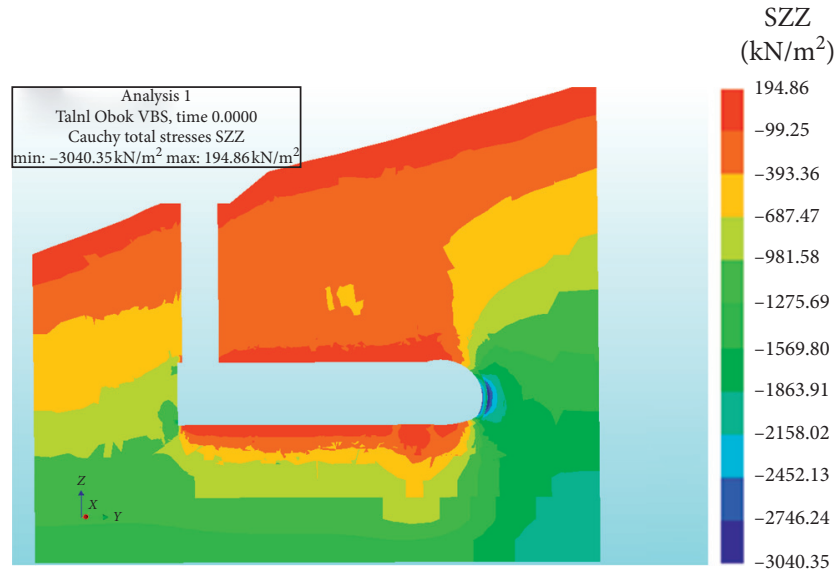

(a)

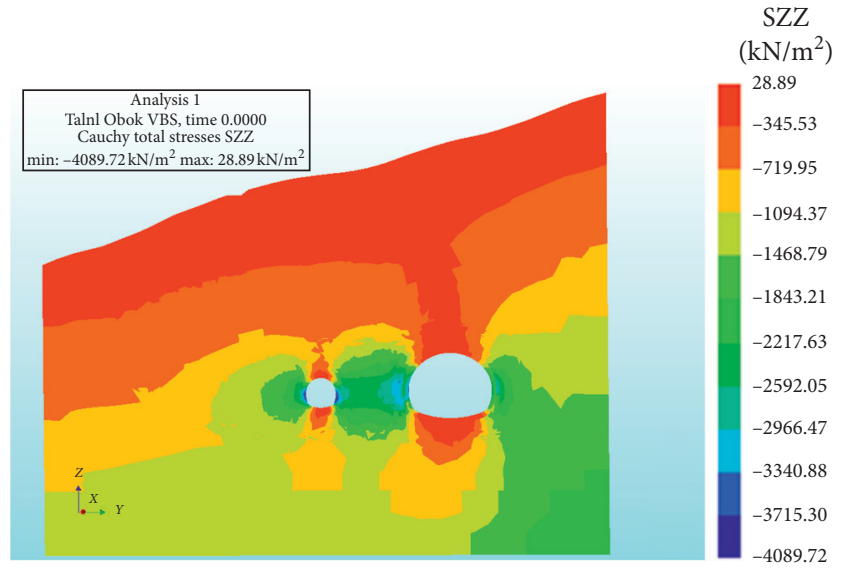

(b)

Figure 17: Total vertical stresses in two cross sections after tunnel excavation.

\section{Discussion and Conclusions}

In summary, the transfer of the tunnel excavation geometry from the BIM model to the FEM analysis software according to the proposed method was successful. Although a completely error-free exchange of geometry is still difficult, we have succeeded in preparing a working process to define geometry in such a way that it can be transferred from the information model without special corrections and further used for the subsequent computational analysis. It is true that the geometry has to be designed specifically for the computational model, but since this process is almost automated, much less effort is required. This means that the proposed approach is considerably better in terms of time efficiency if compared to creating a new tunnel geometry in a FEA program or correcting the imported geometry of the BIM model.
The transfer of the geometry of the geological structure of the ground was not the main focus of this study. Nevertheless, it was shown that the combined transfer of tunnel geometry and geological structure into the FEM software can be successfully performed. Similar to the geometry of the tunnel, a new model has to be created here that is suitable for use in the computational model. This procedure is somewhat simpler than defining the tunnel geometry, because only surfaces that represent the boundaries between different ground layers are needed. However, these boundaries are interpreted by geologists on the basis of a limited number of ground investigation results and are therefore subject to uncertainties. For this reason, accuracy is somewhat less important here. If the interpretation of the geological structure of the soil and rock mass changes during tunnel construction, the proposed methodology enables fast modification of calculation model using the new 
interpretation of the ground composition and existing geometric definition of the tunnel and its excavation sequence.

With a successful analysis in DIANA FEA, the research demonstrates that building a computational model using Dynamo is appropriate and can be used to optimize the preparation of a computational model of a tunnel. This avoids manual remodelling. Any further changes are modelled quickly, as only the relevant inputs need to be changed.

The proposed solution is not based on the IFC standard, as the conversion of the information model into a computational model would go beyond the scope of this project. At the same time, the IFC format is implemented differently in various tools and the version used depends on the individual software. While research on the challenges presented in this paper is progressing, the use of open standards for successful interoperability in infrastructure projects is high on our list of priorities.

As part of the preparation of the presented research, we investigated the possibilities of a more efficient use of information and ground model data for the needs of mechanical analysis of tunnelling according to FEM. The results of the research show that there are currently no simple solutions for interoperability between different BIM and FEM software tools for tunnels. The problem of changes in geometry, remodelling, and simultaneous changes in both models is also not solved yet due to the lack of connections required. These findings are consistent with another recent study [31] that concludes that interoperability between BIM and FEM deserves further attention and technical developments. The exchange methodology we developed is specific to the set of software tools used.

For the most part, the use of a general tunnel information model for the purpose of FEM analysis remains impractical for the time being due to the uncertainty of geometry conversion and the inability to import nongeometric data. However, better geometry modelling tools found in the BIM software are useful for preparing a computational model. In the presented research we have shown that it is possible to prepare the geometry of the tunnel in the BIM software, transfer it, and use it in the software for structural analysis. Furthermore, a ground model can be prepared in a similar way.

In the presented work process, the transformation of the information model into a computational model remains the work of the engineer and is not a question of the algorithm. Nevertheless, after determining the excavation cross section for the computational model and other necessary input data, the rest of the definition of geometry of computational model is automated using a Dynamo script. This makes the preparation of the tunnel geometry for FEM analysis much easier and faster. The exchange of data based on the DWG files proved to be efficient, as the mathematical description of the geometry was preserved, which enabled the further preparation of the model in the analysis software. Due to the fast preparation of the geometry of the new model, the approach presented in this research is useful in practice. Such a working process of tunnel geometry preparation and data transfer was programmed and tested with the software tool for computational analysis DIANA FEA and is applicable to other software solutions that allow the import of volume geometry via DWG data set.

\section{Data Availability}

The developed Dynamo scripts and base data for use cases are not freely available due to legal concerns and commercial confidentiality. Nevertheless, all the concepts and procedures are explained in the presented research and parts of the research may be available upon request.

\section{Conflicts of Interest}

The authors declare that they have no conflicts of interest.

\section{Acknowledgments}

The authors thank iC Consulenten Ziviltechniker (Bergheim bei Salzburg, Austria) and ELEA iC (Ljubljana, Slovenia) for their invaluable participation and continuous support during this research. The presented work was in part financially supported by the iC Consulenten Ziviltechniker (Bergheim bei Salzburg, Austria) and by the Slovenian Research Agency.

\section{References}

[1] A. Costin, A. Adibfar, H. Hu, and S. S. Chen, "Building information modeling (BIM) for transportation infrastructure-literature review, applications, challenges, and recommendations," Automation in Construction, vol. 94, pp. 257-281, 2018.

[2] C. Eastman, P. Teicholz, R. Sacks, and K. Liston, BIM Handbook: A Guide to Building Information Modeling for Owners, Managers, Designers, Engineers and Contractors, John Wiley \& Sons, Hoboken, NJ, USA, 2011.

[3] J. Rammant, "Interoperability for BIM: a structural engineering viewpoint," June 2015.

[4] T. Cerovsek, "A review and outlook for a 'building information model' (BIM): a multi-standpoint framework for technological development," Advanced Engineering Informatics, vol. 25, no. 2, pp. 224-244, 2011.

[5] P. Kontothanasis, V. Krommyda, and N. Roussos, "BIM and advanced computer-based tools for the design and construction of underground structures and tunnels," Tunnel Engineering-Selected Topics, 2019.

[6] T. Froese, "Construction process technologies: a meta-analysis of Canadian research," Canadian Journal of Civil Engineering, vol. 36, no. 3, pp. 480-491, 2009.

[7] Ž. Turk, "Ten questions concerning building information modelling," Building and Environment, vol. 107, pp. 274-284, 2016.

[8] National Institutes of Health (US), Technical Manual for Design and Construction of Road Tunnels-Civil Elements, AASHTO, Washington, DC, USA, 2009.

[9] B. Maidl, M. Thewes, and U. Maidl, Handbook of Tunnel Engineering I: Structures and Methods, Ernst \& Sohn, Berlin, Germany, 1st edition, 2013.

[10] R. Bolghonabai, M. F. Hossaini, M. Mohammadi, and A. Nazem, "On the selection of an appropriate excavation pattern for urban tunnels with big cross-section: a case study," 
International Journal of Mining and Geo-Engineering, vol. 49, no. 2, pp. 297-307, 2015.

[11] G. Swoboda, M. Marence, and I. Mader, "Finite element modelling of tunnel excavation," International Journal of Engineering Modelling, vol. 6, pp. 51-63, 1994.

[12] S. Shreedharan and P. H. S. W. Kulatilake, "Discontinuumequivalent continuum analysis of the stability of tunnels in a deep coal mine using the distinct element method," Rock Mechanics and Rock Engineering, vol. 49, no. 5, pp. 1903-1922, 2016.

[13] G. D. Manolis and D. E. Beskos, "Dynamic response of lined tunnels by an isoparametric boundary element method," Computer Methods in Applied Mechanics and Engineering, vol. 36, no. 3, pp. 291-307, 1983.

[14] F. Beirnaert and A. Lippens, "Analysis of the interoperability from BIM to FEM," Master's thesis, Tampere University of Applied Sciences, Construction Engineering, Tampere, Finland, 2018.

[15] MIDAS GEOTECH, 2020, https://www.midasgeotech.com/.

[16] DIANA FEA, 2020, https://dianafea.com/.

[17] ZSoil, 2020, https://www.zsoil.com/.

[18] PLAXIS, 2020, https://www.plaxis.com/.

[19] Itasca Consulting Group, 2020, https://www.itascacg.com/.

[20] J. I. Israelsson, "Short descriptions of UDEC and 3DEC," in Developments in Geotechnical Engineering, O. Stephansson, L. Jing, and C.-F. Tsang, Eds., vol. 79, pp. 523-528, Elsevier, Amsterdam, Netherlands, 1996.

[21] W. Zhou, H. Qin, J. Qiu et al., "Building information modelling review with potential applications in tunnel engineering of China," Royal Society Open Science, vol. 4, no. 8, Article ID 170174, 2017.

[22] A. Balasubramanian, Geotechnical Investigations for Tunnelling, University of Mysore, Mysore, India, 2016.

[23] S. Fabozzi, G. Cipolletta, E. Capano, D. Asprone, G. Dell'Acqua, and E. Bilotta, "BIM-FEM interoperability for the modelling of a traditional excavated tunnel," in Tunnels and Underground Cities: Engineering and Innovation Meet Archaeology, Architecture and Art (Word Tunnel Congress, Naples 3-9 May 2019)CRC Press, Boca Raton, FL, USA, 2019.

[24] F. Fedorik, T. Makkonen, and R. Heikkilä, "Integration of BIM and FEA in automation of building and bridge engineering design," in Proceedings of the 33rd International Symposium on Automation and Robotics in Construction (ISARC), pp. 735-741, Auburn, AL, USA, July 2016.

[25] T. Rácz and T. Olofsson, "Interoperability challenges of an engineering software provider," in Managing IT in Construction/Managing Construction for Tomorrow, A. Dikbas, E. Ergen, and H. Giritli, Eds., pp. 293-304, CRC Press, Boca Raton, FL, USA, 2009.

[26] M. Maamoun, "Investigation and characterization of building information modeling data," Master thesis, Technische Universität Dresden, Faculty of Civil Engineering, Institute of Construction Informatics, Dresden, Germany, 2018.

[27] T. Dravai, H. Khalyar, and G. Nagy, "The effect of interoperability between BIM and FEM tools on structural modeling and analysis," Master thesis, Project Library, Aalborg University, Aalborg University, Aalborg, Denmark, 2016.

[28] T. Racz and T. Olofsson, Interoperability Challenges of an Engineering Software Provider, Luleå University of Technology, Luleå, Sweden, 2009, http://urn.kb.se/resolve?urn=urn: nbn:se:Itu:diva-35002.

[29] Revit-BIM Software, 2020, https://www.autodesk.com/ products/revit/overview.
[30] Robot Structural Analysis Professional-Structural Analysis Software, 2020, https://www.autodesk.com/products/robotstructural-analysis/overview.

[31] S. Fabozzi, A. A. Biancardo, R. Veropalumbo, and E. Bilotta, "I-BIM based approach for geotechnical and numerical modelling of a conventional tunnel excavation," Tunnelling and Underground Space Technology, vol. 108, Article ID 103723, 2021. 